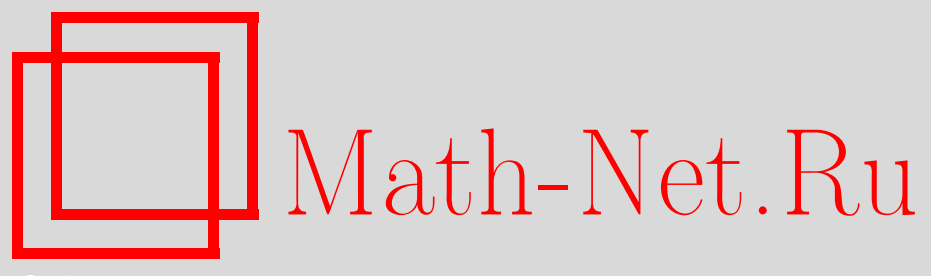

В. В. Козлов, Новиковский день в Математическом институте, УМH, 2008, том 63, выпуск 6, 3-6

DOI: https://doi.org/10.4213/rm9241

Использование Общероссийского математического портала Math-Net.Ru подразумевает, что вы прочитали и согласны с пользовательским соглашением http://www . mathnet.ru/rus/agreement

Параметры загрузки:

IP: 54.81 .137 .203

26 апреля 2023 г., 15:35:59

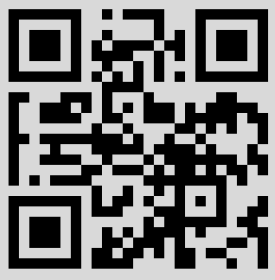




\title{
Новиковский день в Математическом институте
}

\section{В. В. Козлов}

\author{
Уважаемый Сергей Петрович! \\ Уважаемые коллеги, дорогие друзья!
}

Сегодня в Москве ненастный день, с утра идет дождь. А в Математическом институте им. В. А. Стеклова день совершенно замечательный - Новиковский день. Сегодня мы чествуем выдающегося математика современности, крупнейшего российского ученого академика С. П. Новикова.

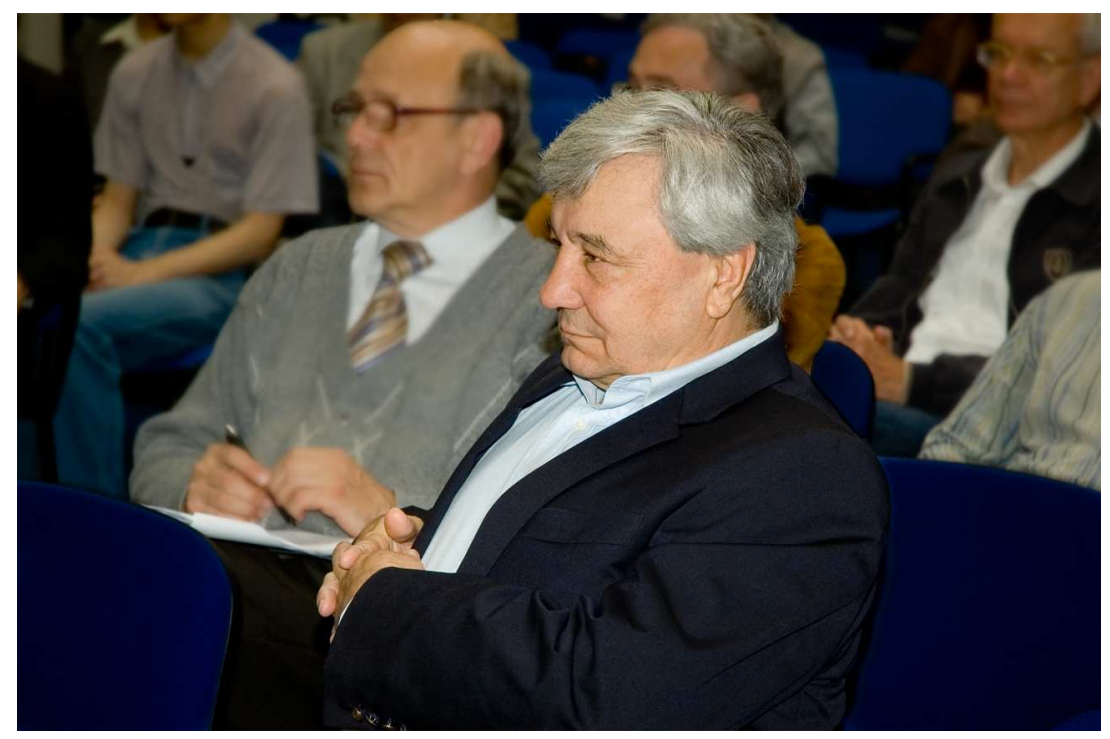

Сознательно допуская вольность речи, скажу, что Сергей Петрович "родился и вырос" в МИАНе. Его выдающиеся родители - академик П. С. Новиков и профессор Л.В. Келдыш работали в нашем институте. И первые свои замечательные результаты по алгебраической топологии С. П. Новиков получил, работая в МИАНе.

Выступление на открытии международной математической конференции в МИАНе (3 июня 2008 г.), посвященной 70-летию академика С. П. Новикова.

(C) В. В. Козлов, 2008 
В первую очередь следует упомянуть о достижении Сергея Петровича, связанном с доказательством топологической инвариантности рациональных классов Понтрягина. Затем последовали замечательные результаты по теории расслоенных пространств, в том числе и по теории слоений. Упомяну известную теорему Новикова о компактном слое на трехмерной сфере. За эти выдающиеся результаты С. П. Новиков первым из российских математиков был удостоен филдсовской медали - высшей международной математической награды, а также ему была присуждена Ленинская премия - высшая научная награда в нашей стране. Сергей Петрович уникально рано (ему еще не было 30) был избран членом-корреспондентом АН СССР.

Через некоторое время С. П. Новиков, как и его великие предшественники по топологии Риман и Пуанкаре, обратился к проблемам теоретической и математической физики. Это его увлечение оказалось устойчивым и очень плодотворным. Он справедливо считает, что широкое развитие математики невозможно без тесного взаимодействия с естественными науками, прежде всего с физикой.

Собственно, дискуссия о путях развития математики состоялась уже давно в рамках известных докладов Пуанкаре и Гильберта на первом и втором международных математических конгрессах. Пуанкаре настаивал на том, что только систематический анализ проблем современной теоретической физики даст импульс новым задачам и идеям в математике. Не отрицая полезность такого взаимодействия, Гильберт проводил мысль о внутренней логике развития математического знания, сформулировав ставший знаменитым перечень актуальных математических проблем и поставив на передний план проблемы аксиоматического обоснования математических теорий. Если говорить кратко, то победил план Гильберта, оказав решающее влияние на развитие математики в течение многих десятков лет.

Кстати сказать, начиная с 1910-х годов в центральных математических журналах фактически прерывается поток статей по математической физике и теоретическим вопросам механики, оставив свое место исследованиям по теоретико-множественной математике. В этом смысле поучительна математическая судьба Э. Цермело, известного своими исследованиями по аксиоматике теории множеств. В действительности он начал свою научную карьеру как ассистент М. Планка, занимаясь различными проблемами теоретической физики, в частности, вопросами статистической механики (вспомним известный парадокс Цермело). Его докторская диссертация посвящена гидродинамике идеальной жидкости на сфере, в том числе исследованию эволюции системы точечных вихрей. K сожалению, эта работа практически забыта, и многие (но не все!) его результаты переоткрыты и опубликованы совсем недавно. Затем, под обаянием идей Гильберта, Цермело полностью переключился на занятия абстрактной математикой.

Первые исследования по математической физике С. П. Новиков выполнил по общей теории относительности, исследуя нестационарные "космологические" 
решения уравнений ОТО. Затем выяснилось, что эти методы можно эффективно применить к задачам аэродинамики. Крупные и яркие достижения Сергея Петровича и его учеников были получены в проблеме точного интегрирования уравнений математической физики и механики. С одной стороны, развитые Сергеем Петровичем методы прояснили и обобщили результаты по точному интегрированию задач механики в работах классиков XIX века (Ковалевская, Клебш, Нейман и др.), с другой - привели к новым идеям и результатам по представлению решений с помощью $\theta$-функций и их естественных обобщений. Еще один важный вклад С. П. Новикова в математику - это вариационное исчисление для многозначных функционалов. К задачам подобного вида приводит, в частности, поиск периодических траекторий в системах с симметриями: после редукции функционал действия становится многозначным. Аналогичные проблемы возникают и при описании движения заряженных частиц в стационарных магнитных полях. Оригинальные результаты Сергея Петровича обогатили вариационное исчисление в целом и привели к теории Морса-Новикова для многозначных функционалов, в которой топологические соображения играют центральную роль. Они нашли многочисленные приложения в различных конкретных задачах, в частности, в задаче о периодических решениях уравнений Кирхгофа, описывающих динамику твердого тела в безграничном объеме идеальной жидкости. Упомяну еще один круг задач, который С. П. Новиков “вытащил из физиков" (как он сам однажды выразился) это исследование поверхностей Ферми в теории твердого тела. В частности, сюда примыкает интересная задача Новикова об изучении динамических систем с многозначными интегралами.

Свои идеи о взаимодействии математики и физики Сергей Петрович пытался претворить и в преподавании на мехмате Московского университета. По его инициативе был проведен эксперимент: в рамках отделения математики был создан экспериментальный поток со своим учебным планом. Душой и главной движущей силой этого эксперимента был, конечно, сам Сергей Петрович. Он тщательно подбирал состав лекторов и преподавателей, тщательно продумывал учебный план и программы курсов. Этот уникальный эксперимент дал свои несомненно положительные результаты: появились обновленные программы основных математических курсов, появились новые учебники. Однако, к сожалению, все эти положительные моменты в итоге не привели к радикальному изменению стиля преподавания на факультете. Для этого надо было постоянно иметь "мотор" в лице С. П. Новикова.

Сергей Петрович создал большую и влиятельную в мире научную школу по топологии и математической физике. Его многочисленные ученики работают в МГУ, МИАНе и во многих известных мировых научных центрах. Сегодня мы будем, в основном, слушать доклады его прямых учеников. Сергей Петрович разносторонне одарен. Он легко переходит к новым для него областям исследования. Совсем недавно на общеинститутском семинаре Сергей Петрович 
сделал очень интересный доклад по дискретному комплексному анализу. Он продолжает активно и результативно работать в разных областях математики. Его успехи недавно отмечены престижной международной премией Вольфа за математические достижения. Сергей Петрович интересуется не только математикой. Его эрудиция восхищает. Он много знает, много помнит и очень интересно рассказывает. В этом, я думаю, мы еще не раз убедимся на приеме вечером в его честь.

От имени сотрудников Математического института я еще раз поздравляю дорогого Сергея Петровича с его семидесятилетием. Мы все желаем ему прежде всего доброго здоровья, благополучия и дальнейших творческих достижений. Мы гордимся тем, что в нашем институте работает такой выдающийся и признанный во всем мире математик, как Сергей Петрович Новиков. 